\title{
Estrategias y experiencias del movimiento obrero en una región de la Patagonia argentina: el noreste de Chubut 1983-1990
}

\author{
Strategies and experiences of the labor movement in a region of Argentine \\ Patagonia: the northeast of Chubut 1983-1990
}

Gonzalo Pérez Álvarez*

Resumen: Se investigan las características de los principales agrupamientos sindicales en los que buscó organizarse la clase obrera en la Patagonia argentina, específicamente en la región noreste de Chubut desde 1983 a 1990. Para ello debato, desde datos concretos sobre la conflictividad social, con las teorías más difundidas en los '80 y '90s, que afirmaban la pérdida de relevancia de la clase obrera y del movimiento obrero organizado. La investigación aporta a varios debates en el seno de los estudios sobre clase obrera en Argentina y América Latina. Estos aportes se realizan desde una región que expresa una especificidad histórica, a partir de ser receptora de uno de los polos de industrialización subsidiada de Argentina.

Palabras Clave: Disputa sindical; Patagonia argentina; Izquierda; Transición

\begin{abstract}
I investigate the characteristics of the main union groups in which the working class sought to organize in the Argentine Patagonia, specifically in the northeast region of Chubut from 1983 to 1990. To this end, I discuss, from concrete data on social conflict, with the most widespread theories in the '80s and' 90 s, which affirmed the loss of relevance of the working class and organized labor movement. The research contributes to several debates inside the studies on working class in Argentina and Latin America. These contributions are made from a region that expresses a historical specificity, from being a recipient of one of Argentina's subsidized industrialization poles.
\end{abstract}

Keywords: Trade union dispute; Argentine Patagonia; Left; Transition

Recibido: 29 abril 2018 Aceptado: 4 junio 2018

\footnotetext{
Argentino. Doctor en Historia, Director del Instituto de Investigaciones Históricas y Sociales de la Universidad Nacional de la Patagonia. Investigador del Consejo Nacional de Investigaciones Científicas y Técnicas. Docente de la Universidad Nacional de la Patagonia Sede Trelew. Mail: gperezalvarez@gmail.com
} 


\section{Introducción}

En este artículo exploro los diferentes agrupamientos sindicales en los que se organizaron algunas fracciones de la clase obrera durante la década de los '80 en una región de la Patagonia argentina ${ }^{1}$. En particular enfoco mi atención en el noreste de Chubut ${ }^{2}$, el territorio donde se implantó un polo industrial desde mediados de los años '50.

En lo cronológico me concentro en el período que transcurre desde el retorno al régimen constitucional de gobierno, hacia fines de 1983 y tras más de siete años de dictadura militar, hasta el año inicial de la década del ' $90^{3}$. Para ello realizo un doble proceso: por un lado observo la dinámica general de conflictividad social en la región; por otro hago foco en los dos sindicatos más importantes de la región durante esos años, la $\mathrm{AOT}^{4}$ y la $\mathrm{UOM}^{5}$, analizando las agrupaciones que se conformaron, las diputas que se desarrollaron al interior de cada sindicato y cómo ellas tuvieron relación, e incidieron, en el proceso general.

Se desarrollaba por entonces un relevante debate sobre los procesos de "normalización sindical" y los modelos de sindicatos a construir en el marco del retorno al régimen constitucional. En el mismo intervinieron diversos agrupamientos de trabajadores, protagonizándose reñidas elecciones en los principales sindicatos de la región que conmovieron políticamente a gran parte de la sociedad y a casi la totalidad de los obreros.

La investigación aporta a varios debates en el seno de los estudios sobre clase obrera en América Latina: cuál fue el rol de la clase obrera en los procesos nominados por la historiografía tradicional como de "transición a la democracia"6; cuáles fueron los cambios y continuidades en la clase a partir del cambio en la forma de ejercicio de la dominación política

\footnotetext{
${ }^{1}$ Se entiende por Patagonia argentina, a las provincias de Neuquén, La Pampa, Río Negro, Chubut, Santa Cruz y Tierra del Fuego. Hago hincapié en la Patagonia Sur, que agrupa las últimas tres provincias.

${ }^{2}$ Subregión integrada por los departamentos administrativos de Rawson y Biedma, al norte de Chubut. Fue la zona con desarrollo industrial, en las ciudades de Trelew, Rawson y Puerto Madryn, a partir del proyecto de industrialización subsidiada.

${ }^{3}$ Para analizar el proceso previo, ver Leandro Molinaro, "El reposicionamiento de la burocracia sindical en el ocaso del 'Proceso'(julio de 1982-diciembre de 1983", Archivos de Historia del Movimiento Obrero y la Izquierda N8, Buenos Aires, ProHMOI, 2016, 33-54; y Sebastián Guevara, "Lucha de clases y acumulación de capital en Argentina 1973-1983: discusiones a partir de los estudios sobre la acción política obrera", Izquierdas, 33, Santiago, IDEA-USACH, mayo 2017, 66-89. Sobre el año 1991 como un momento de quiebre clave (que hace explicable el límite planteado en 1990), ver Alberto Bonnet, La hegemonía menemista, Buenos Aires, Prometeo, 2008; Gonzalo Pérez Álvarez, "Lucha y memoria obrera en el noreste del Chubut. Una aproximación desde la fábrica Modecraft 1990-1991” en Historia Antropología y Fuentes Orales, № 41, Barcelona, 2009, 25-48. Norma Giarracca, "Argentina 1991-2001: Una década de protesta que finaliza en un comienzo. La mirada desde el país interior", Argumentos, 1 (1), diciembre 2002,

http://www.revistaargumentos.com.ar/index.php/argumentos/article/viewFile/23/20

${ }^{4}$ Asociación Obrera Textil, agrupa a los obreros de base de la rama textil.

${ }^{5}$ Unión Obrera Metalúrgica, integra a los obreros de la rama metalúrgica.

${ }^{6}$ Ver Rodrigo Araya, Del combate a la dictadura a la preservación de la democracia. Movimiento sindical y políticas de concertación social. Los casos de Chile y España (1975-1994), Tesis Doctoral Univ. Autónoma de Barcelona, en http://www.tesisenred.net/bitstream/handle/10803/96357/rag1de1.pdf?sequence=1, 2012; Leandro Molinaro, Demonización y Reconciliación nacional, Buenos Aires, Colisión, 2013; Patricio Ruiz, "Hacia una 'transición modelo': influencia y significación de la transición española en la oposición chilena a la dictadura (1980-1987)", Izquierdas, 24, Santiago, IDEA-USACH, julio 2015, 127-149.
} 
en el país ${ }^{7}$; en qué condiciones emergió la clase de la dictadura (debate que hace referencia a la noción de "derrota" y a su necesaria periodización) ${ }^{8}$; cuáles fueron las diferencias en torno al modelo sindical de las listas que se postulaban como "combativas y anti burocráticas" ${ }^{9}$ con respecto a las conducciones sindicales tradicionales; y qué elementos nos aportan los procesos analizados para la discusión sobre lo que se suele nominar "relación bases-dirigencias"10.

Estos aportes se realizan desde una región que expresa una especificidad histórica, a partir de ser receptora de uno de los polos de industrialización subsidiada impulsados durante décadas previas. Durante los años aquí investigados ese proyecto parecía exitoso, en términos de crecimiento demográfico e industrial para Chubut; las dos fracciones obreras que analizo en mayor detalle (textiles y metalúrgicos) desarrollaban su labor en torno a fábricas instaladas al abrigo de esa política estatal de impulso a la promoción industrial.

Expondré un análisis de la conflictividad social en la región noreste de Chubut durante el período, a fin de enfocar las propuestas sindicales investigadas en ese marco contextual. Entiendo que la caída de la dictadura militar, y el retorno al régimen constitucional desde el 10 de diciembre de 1983, promovió nuevas posibilidades de dinamizar los conflictos, que hasta allí tendían a ser menos visibles, especialmente durante la etapa de mayor represión.

Realizo un rastreo general de los principales conflictos, un análisis cuantitativo de los mismos, y una periodización para comprender los cambios cualitativos. Son elementos claves a fin de definir las condiciones en las cuáles la clase obrera, y demás grupos subalternos, se encontraron con las transformaciones impuestas durante la década del '90.

\footnotetext{
7 Pablo Belardinelli, "El marco político de la conflictividad obrera", Ernesto Villanueva (coord.), Conflicto Obrero. Transición política, conflictividad obrera y comportamiento sindical en la Argentina 1984-1989, Buenos Aires, UNQ, 1994, 103-149; Ernesto Villanueva (coord.) Conflicto obrero. Transición política, conflictividad obrera y comportamiento sindical en la Argentina 1984-1989, Buenos Aires, UNQ, 1994; Fernando Aiziczon, "Construyendo tradiciones. Activistas de izquierda en las luchas de los obreros de la construcción de Neuquén a fines de los años '80", Izquierdas, 5, Santiago, IDEA-USACH, julio 2009.

${ }^{8}$ Pablo Ghigliani, "La noción de derrota en la historia reciente del movimiento obrero argentino", Actas $V$ Jornadas de Sociología de la UNLP, La Plata, UNLP, en https:/www.aacademica.org/000-096/570.pdf; G. Pérez Álvarez, "Dictadura, democracia y clase obrera: los trabajadores ante el retorno al régimen constitucional en el noreste de Chubut", Avances del CESOR, № 12, Rosario, UNR, Primer semestre 2015, 71-88. Pablo Pozzi y Alejandro Schneider, Combatiendo el capital: Crisis y Recomposición de la clase obrera argentina (1985-1993), Buenos Aires, El Bloque Edit., 1994, 20.

9 Agustín Prospitti, "El sindicalismo combativo en la Unión Obrera Metalúrgica Villa Constitución y el desafío de su reorganización en el retorno de la democracia", Izquierdas, 24, Santiago, IDEA-USACH, julio 2015, 82-107; Fernando Aiziczon, "Trayectorias militantes, izquierda y política sindical: la intervención del MAS en Sierra Grande a través de las vivencias de un obrero minero, Patagonia argentina (1988-1991)", Izquierdas, 31, Santiago, IDEA-USACH, diciembre 2016, 46-70.

${ }^{10}$ Entre otras producciones, ver los recientes dossiers sobre la noción de burocracia sindical en el número 7 de la revista "Nuevo Topo" (Buenos Aires, 2010) y en el número 8 de la revista "Archivos del Movimiento Obrero y la Izquierda" (Buenos Aires, 2016). Aun más recientes, ver Ianina Harari, "¿Qué es la burocracia sindical?", Razón y Revolución 30, Buenos Aires, CEICS, 2017, 51-67; Agustín Santella, "El debate sobre bases contra direcciones sindicales revitalizado", Estudios del Trabajo, Buenos Aires, ASET, 2017, http://www.scielo.org.ar/pdf/et/n53/n53a04.pdf.
} 


\section{Breve contexto, fuentes y debates}

Entiendo que aún no contamos con una producción historiográfica suficiente sobre los '80, ni en Argentina ni en el conjunto de América Latina ${ }^{11}$. El regreso al régimen constitucional tras siete años de dictadura, los debates acerca de la noción de derrota en la clase obrera y la emergencia de una relevante dinámica de conflictividad política-sindical entre los obreros, plantean una necesaria revisión crítica a esa década de gran riqueza. Observar, en este caso, una porción de la Patagonia argentina implica acercarse a una región caracterizada por una continua migración, con una clase obrera "joven” o "en formación”. Esto plantea particularidades que complejizan la mirada sobre el período.

Para construir la columna vertebral del relato y el registro sistemático de conflictos sociales trabajé con un archivo basado en el registro de publicaciones periodísticas de la región. Además, he consultado archivos gubernamentales y fuentes menos exploradas, como entrevistas a trabajadores, documentos partidarios y actas de sindicatos.

Ha sido clave el aporte de las entrevistas a militantes obreros que fueron parte de estos procesos. La construcción de fuentes orales brindó parte del significado que tuvieron estos hechos para los sujetos que los desarrollaron y especialmente logran hacer observables los complejos y moleculares ${ }^{12}$ procesos que se van desarrollando para converger en una organización o un agrupamiento sindical. Las fuentes escritas, más controladas por el poder,

${ }^{11}$ Eso, obviamente, no implica que no existan producciones de enorme riqueza: sostengo que aún falta profundizar en algunos aspectos que sí están mejor explorados para los años '90. Sobre luchas sociales en Argentina y Chile durante los '80, demarcando algunos artículos recientemente publicados y teniendo en cuenta las diferencias de contexto político: Leandro Molinaro, "La democracia del Nunca más y el movimiento obrero. La ocupación obrera de la planta Ford de General Pacheco en 1985", Archivos de Historia del Movimiento Obrero y la Izquierda N², Buenos Aires, ProHMOI, 2013, 55-76; Christian Matamoros, "Profesores comunistas y sindicalismo docente en la lucha antidictatorial, Chile 1981-1987", Izquierdas, 32, Santiago, IDEA-USACH, marzo 2017, 203-234; Felipe Delgado y Miguel Maugard, "Movilización y organización popular en dictadura: las jornadas de protesta nacional en Arica (1980-1986)", Izquierdas, 39, Santiago, IDEA-USACH, abril 2018, 34-56. Virginia Morales, "Reconfiguraciones identitarias en la Asociación Madres de Plaza de Mayo: lucha contra la impunidad, radicalización y "giro a la izquierda" (1983-2003)", Izquierdas, 34, Santiago, IDEA-USACH, julio 2017, 125-149; Rodrigo Araya, "Ha llegado la hora de decir basta. El movimiento sindical y la lucha por la democracia en Chile, 1973-1990", Izquierdas, 37, Santiago, IDEA-USACH, diciembre 2017, 191-211; Gemita Oyarzo Vidal, "Voces de los 80. De los Actores colectivos a los sentidos históricos de las luchas antidictatoriales en Chile (1973-1989)", Izquierdas, 8, Santiago, IDEA-USACH, 2010, 1-14. Poniendo en diálogo Argentina y Chile, ver G. Pérez Álvarez, "El aporte de la migración chilena a la formación de una nueva clase obrera en el noreste de Chubut: 1956-1989", Cuadernos de Historia, º 43, Santiago, Universidad de Chile, 2015, 59-81; Mónica Gatica, ¿Exilio, migración, destierro? Trabajadores chilenos en el noreste de Chubut (1973-2010), Buenos Aires, Prometeo, 2013; Fernando Aiziczon, "Militantes chilenos en Neuquén. La experiencia de la Interbarrial durante los años '80", Izquierdas 21, Santiago, IDEA-USACH, octubre 2014, 67-82. Específicamente sobre la temática aquí trabajada, ver Mónica Gordillo, "¿Cómo enfrentar a las burocracias sindicales? Algunas estrategias democratizadoras en los 80", Archivos de Historia del Movimiento Obrero y la Izquierda N8, Buenos Aires, ProHMOI, 2016, 55-76

12 En términos de metodología recuperamos el enfoque gramsciano que postula una aproximación "molecular" al proceso. Antonio Gramsci, Notas sobre Maquiavelo, sobre la política y sobre el estado moderno, Buenos Aires, Nueva Visión, 1999, 99. 
suelen ocultar aspectos claves de la organización de las clases subalternas y de las expresiones de conflictividad social.

La necesidad de un mínimo contexto histórico nos lleva a hacer referencia al impulso que desde el estado nacional se dio a la instalación de "polos de desarrollo" en la Patagonia argentina, para promover la llegada de migrantes a una región poco poblada y con escasas perspectivas de crecimiento económico ${ }^{13}$. La política de "polos de desarrollo" se planteaba como la creación de centros industriales que irradiarían el "progreso" hacia las regiones cercanas, en el marco de afirmar la "soberanía" sobre la Patagonia desde formulaciones propias de la Doctrina de Seguridad Nacional. ${ }^{14}$

Desde la década del '60 se impulsó la instalación de fábricas que procesaban fibras textiles sintéticas. En 1971 se creó el Parque Industrial de Trelew y hacia 1973 la rama textil de Chubut ocupaba el segundo puesto nacional en varios rubros del sector ${ }^{15}$. También en 1971 se adjudicó a ALUAR (Aluminio Argentino S.A.) el proyecto de una planta de aluminio primario, que se instaló en Puerto Madryn ${ }^{16}$. En ambos casos la inversión fue aportada por el estado, realizando una enorme transferencia de fondos públicos a empresas privadas.

La última dictadura generó un cambio en la relación de fuerzas sociales que hizo retroceder a la clase obrera, pero no en una proporción tan significativa como para quitarle capacidad de acción autónoma: por eso, para el retorno al régimen constitucional, la utilización de la noción de derrota no es la más adecuada para comprender el accionar del movimiento obrero. Ese concepto sí se hace más operativo para analizar la situación de la clase en la breve fase de hegemonía neoliberal, entre 1990 y fines de 1993: la derrota de la clase se había construido a través de sucesivos avances, que habían modificado la relación de fuerzas sociales; pero a su vez la clase obrera volvería a recuperarse a través del ciclo de rebelión que comenzaría hacia fines de 1993, con el hito del Santiagazo. ${ }^{17}$

Existe un amplio debate sobre el uso de la noción de derrota en la historia reciente del movimiento obrero argentino ${ }^{18}$. La utilización del concepto "derrota" es relevante pero no

13 Para mayor desarrollo ver G. Pérez Álvarez, "Trabajadores y trabajadoras en tres procesos de industrialización acelerada: Manaus (Amazonia-Brasil), Trelew (Patagonia-Argentina) y Vitoria-Gasteiz (País Vasco-España)", en Ayer, Madrid, Marcial Pons, en prensa.

${ }^{14}$ G. Pérez Álvarez, "Amazônia Brasileira e Patagônia Argentina: planos de desenvolvimento e soberania nacional", Estudos Avançados Vol.30 N 88, San Pablo, USP, Setembro-Dezembro 2016, 117-138.

${ }^{15}$ Chubut ocupaba el segundo puesto en medias (15\%, contra $83 \%$ del área metropolitana), tejido de punto (11\% frente al $81 \%$ ) e hilado de fibras textiles (6,4\% ante un $76 \%$ en el área central); Elsa Cimillo, Bloque textil: dinámica en la provincia del Chubut. 1973-1984, Buenos Aires, CFI-CEPAL, 1985, 12-13.

${ }^{16}$ Ver Marcelo Rougier, Estado y empresarios de la industria del aluminio en la Argentina. El caso Aluar, Buenos Aires, UNQ, 2011; Raquel Caprano y Dora Palacios, "Economías de enclave y estrategias empresariales. El Caso Aluar", Actas XII Jornadas Interescuelas Departamentos de Historia, Bariloche, UNCo, 2009; G. Pérez Álvarez, "Paternalismo, experiencia obrera y desarrollo del régimen de gran industria: la historia de ALUAR", Mundos do Trabalho vol.3 n6, julho-dezembro 2011, Universidade Federal de Santa Catarina, 130-150.

${ }^{17}$ Para un análisis general del proceso de rebelión durante los años '90, ver María Celia Cotarelo, Argentina (1993-2010). El proceso de formación de una fuerza social; Buenos Aires, PIMSA-Imago Mundi, 2016. Para un análisis particular del santiagazo, ver M. C. Cotarelo, "El motín de Santiago del Estero. Argentina, diciembre de 1993", PIMSA DT N 19, Buenos Aires, PIMSA, 1999, 83-119.

${ }^{18}$ Sintetizada, parcialmente, en Ghigliani, op. cit. 
definitorio: lo clave es evaluar si estamos ante cambios cualitativos en la correlación de fuerzas sociales, y debatir cómo esto se expresa en la conflictividad social del período.

Pese a esto el debate sobre la derrota tiene relevancia, ya que los trabajos de mayor difusión académica en los años '80, que marcaron la continuidad hacia los '90, daban por hecha la caída del "antiguo" poderío de la clase obrera y sus organizaciones sindicales. La mayoría de esos estudios destacaban la pérdida de centralidad del movimiento obrero organizado y el surgimiento de una pléyade de "nuevos movimientos sociales".

La agenda propuesta por Elizabeth Jelin $^{19}$ para el estudio de la dinámica de conflictividad social en Argentina se entroncó con una corriente que a nivel internacional sostenía esa misma noción de la pérdida de poder de la clase obrera y el movimiento sindical. Autores de poderosa repercusión, como Claus Offe ${ }^{20}$ Alberto Melucci $^{21}$, Alain Touraine ${ }^{22}$, Klaus Eder ${ }^{23}$ y Mancur Olson ${ }^{24}$, entre muchos otros, sostenían que la clase obrera había dejado de ser el sujeto clave de los cambios sociales y de la conflictividad. En Argentina, donde la dictadura arrasó muchas estructuras organizativas de la clase, esta lectura se instaló como parte del sentido común dominante ${ }^{25}$, a un nivel que hacía difícil hasta dar la discusión con esos postulados, especialmente en el seno de las instituciones formales del sistema científico argentino (Universidades, CONICET, y otras) ${ }^{26}$.

Esa postura se entrelazaba con una mirada claramente política: para muchos cuadros dirigentes de los partidos políticos tradicionales era necesario reducir el poder de la clase obrera y, especialmente, de sus construcciones sindicales. Estas eran consideradas rémoras de una sociedad antigua, atrasada, propia del corporativismo y puestas, en muchos discursos de la época, al mismo nivel que la estructura militar. ${ }^{27}$

${ }^{19}$ Elizabeth Jelin (comp.), Los nuevos movimientos sociales, Tomo 1 (Mujeres. Rock Nacional) y Tomo 2 (Derechos Humanos. Obreros. Barrios), Buenos Aires, CEAL, 1985; E. Jelin (comp.) Movimientos sociales y democracia emergente, Tomo 1 y 2, Buenos Aires, CEAL, 1987

${ }^{20}$ Claus Offe, Partidos políticos y nuevos movimientos sociales, Madrid. Edit. Sistema, 1992.

${ }^{21}$ Alberto Melucci, Acción colectiva, vida cotidiana y democracia, México D.F.; Colegio de México, 1999.

${ }^{22}$ Alain Touraine, Los movimientos sociales, Buenos Aires, Almagesto, 1991.

${ }^{23}$ Klaus Eder, "La institucionalización de la acción colectiva. Hacia una nueva problemática teórica en el análisis de los movimientos sociales", Pedro Ibarra y Benjamín Tejerina (edit.) Los Movimientos Sociales. Transformaciones políticas y cambio cultural; Madrid, Trotta, 1998, 337-359.

${ }^{24}$ Mancur Olson, La lógica de la acción colectiva, México, Limusa, 1992.

${ }^{25}$ Gramsci analiza la conformación de un "sentido común" en la sociedad, intentando comprender cómo se construye “...una misma y común concepción del mundo (general y particular, transitoriamente operante -por vía emocional-- o permanente, cuya base intelectual está tan arraigada, asimilada y vivida, que puede convertirse en pasión)" en www.gramsci.org.ar "El lenguaje, los idiomas, el sentido común”. Una concepción del mundo casi incuestionable, ya que no se hace consciente. Develar el sentido común dominante, y cómo emerge de la hegemonía que impuso la clase dominante, es tarea del investigador que analiza los fenómenos de conciencia de las clases, en especial de aquellas en relación de subalternidad.

26 También en la historiografía se construye un "sentido común historiográfico" que pretende naturalizar la hegemonía, instituyendo parámetros hegemónicos acerca de lo que es aceptable o no, en términos de enfoques teóricos y/o de temáticas abordables (Agustín Nieto, "Notas críticas en torno al sentido común historiográfico sobre 'el anarquismo argentino'", A Contracorriente Vol.7, No.3, North Carolina State University, Spring 2010, 219-248).

${ }^{27}$ Uno de los ejes de campaña de Raúl Alfonsín, elegido presidente de Argentina a fines de 1983, fue la denuncia de un "pacto sindical-militar", sosteniendo que se negociaba una amnistía para los genocidas desde "un pacto corporativo" (ver http://www.diarioinedito.com/Nota/14886, o César Díaz y Mario Giménez "La Nación y el sindicalismo en 1983: la crisis, las huelgas y la democratización, Revista internacional de 
Esa era la perspectiva dominante en el seno del "alfonsinismo" 28 , el movimiento político que encabezaba el electo presidente del país Raúl Alfonsín, quién inauguró el período más extenso de gobiernos constitucionales de la historia argentina. La "ley de reordenamiento sindical y régimen electoral", conocida como "ley Mucci ${ }^{29}$ ", discursivamente buscaba la democratización de las elecciones de autoridades sindicales y la inclusión de las minorías en la dirección, pero su verdadera intención era debilitar la hegemonía del peronismo en los principales sindicatos. Esa ley era considerada clave para Alfonsín, tanto que fue enviada al congreso el 16 de diciembre de 1983, apenas seis después de asumir su mandato. Tras un rápido tratamiento en diputados, donde el radicalismo impuso su mayoría, el proyecto fue derrotado en el senado, en una reñida votación finalizada en 24 negativos y 22 afirmativos.

La perspectiva académica que pretendía licuar la relevancia social del sindicalismo confluía con esta intencionalidad política; o bien era parte de la misma. Por otro lado diversos estudios sobre el movimiento obrero, si bien evidenciaban su relevancia, lo hacían reduciéndolo al lugar de corporación: su mirada se anclaba a lo institucional, sus dirigentes, las negociaciones con el estado y los gobiernos, y, en muy contadas ocasiones, atendía a los procesos de lucha. ${ }^{30}$ Una perspectiva que "acusaba" al movimiento obrero de "corporativo", pero limitaba su investigación al aparato administrativo sindical.

\section{Una sintesís del proceso centrado en lo cuantitativo}

Volcaré aquí el registro de los hechos de conflictividad social en el noreste del Chubut entre 1984 y 1990, construido a partir del relevamiento del Diario Jornada (inaugurado en

Historia de la Comunicación, $\mathrm{N}^{\circ}$ 9, 2017, 92-107). Este último texto, junto al citado libro de Leandro Molinaro, Demonización $y \ldots$ (que analiza la centralidad del diario Clarín en la configuración de la representación hegemónica de la transición a la democracia en Argentina), muestran el rol político clave de los grandes medios en la etapa investigada.

${ }^{28}$ Ver Gabriel Vommaro, "Cuando el pasado es superado por el presente: las elecciones presidenciales de 1983 y la construcción de un nuevo tiempo político en Argentina", Alfredo Pucciarelli (coord.), Los años de Alfonsín ¿El poder de la democracia o la democracia del poder?, Buenos Aires, Siglo XXI, 2006, 245-288.

${ }^{29}$ Apellido del ministro de trabajo durante ese primer período de gobierno, Antonio Mucci. Durante la última dictadura militar fue uno de los fundadores del Movimiento Nacional de Renovación Sindical y tras la derrota de su proyecto de ley renunció a su cargo. Ver la tesis de Juan Pedro Massano, Reorganización del Movimiento Obrero Sindicalizado en la posdictadura argentina: El caso de la "Ley Mucci", FHACE-UNLP, 2012, http://www.memoria.fahce.unlp.edu.ar/tesis/te.707/te.707.pdf y Eugenia Aruguete, "Lucha política y conflicto de clases en la posdictadura. Límites a la constitución de alianzas policlasistas durante la administración Alfonsín", Alfredo Pucciarelli (coord.), Los años de Alfonsín ¿El poder de la democracia o la democracia del poder?, Buenos Aires, Siglo XXI, 2006, 413-460.

30 Quizás el de mayor repercusión en Argentina fue Arturo Fernández, Las prácticas sociopolíticas del sindicalismo Tomo 1 y 2 (1955-1985), Buenos Aires, CEAL, 1988. Encontramos un enfoque similar en Julio Godio (comp.), El debate sindical nacional e internacional, Buenos Aires, CEAL, 1984; Osvaldo Calello y Daniel Parcero, De Vandor a Ubaldini. Tomo 1 y 2, Buenos Aires, CEAL, 1984. Esa perspectiva institucionalista fue hegemónica en los estudios más difundidos sobre el movimiento obrero argentino. Nicolás Iñigo Carrera la crítica en "La otra estrategia. La voluntad revolucionaria (1930-1935)" (Buenos Aires, Imago Mundi, 2016) ejemplificándola, entre otros, en Hiroshi Matsushita (Movimiento obrero argentino 1930-1945, Buenos Aires, Hyspamérica, 1986), un autor estrictamente encorsetado al aparato institucional de los sindicatos y partidos políticos. 
1954, y desde esa fecha con circulación diaria hasta el presente). El observable fue el hecho ${ }^{31}$, que también es la unidad de registro, definido como "todo hecho colectivo de protesta o de lucha, llevado a cabo por personificaciones de categorías económicas, sociales o políticas, dirigido contra alguna expresión del estado de cosas existente" ${ }^{32}$. Analizo los sujetos que los desarrollaron, las organizaciones convocantes y la forma de los conflictos. Buscó así que el análisis pueda ser comparado con el proceso nacional en Argentina, y por ello tomo como esquema de registro general al que sigue el PIMSA. ${ }^{33}$

Delimito como un primer período al bienio 1984-85, años de aguda conflictividad, cuya clave es la salida de la dictadura y el retorno al régimen constitucional. Se suceden permanentes conflictos laborales por recomposición salarial y mejores condiciones de trabajo; es importante el nivel de movilización en torno al proceso de normalización sindical. En el plano local son años donde aún se expresa un auge del proyecto industrialista, aunque se comenzaban a evidenciar algunos problemas por la nueva orientación en política económica que iba ganando peso en el gobierno nacional ${ }^{34}$.

El siguiente período abarca los años 1986-87-88. Aquí se ubica la bisagra histórica entre el anterior modelo, que promovía la expansión industrialista en la región, y el nuevo esquema, donde las pequeñas y medianas industrias serían desplazadas. Si bien 1986 aún sostiene características de conflictividad semejantes a las del período previo ya se vislumbraban elementos propios de la fase posterior.

El momento de quiebre clave del lapso temporal investigado, fueron los años 1989-90: allí se consolidaron los procesos de transformación socioeconómica. Si la fase anterior puede entenderse como bisagra, aquí el polo desarrollista fue desmantelado. ${ }^{35}$

Hasta el '85 fueron claves los conflictos por la normalización sindical, con acciones de solidaridad entre diferentes colectivos laborales. Esto empieza a modificarse en 1986; en ese año se aceleró la caída del polo (vía cancelación de nuevos proyectos) y el cambio empezó a hacerse inocultable hacia 1987-88. Se produjeron diversas luchas contra cierres de fábricas, que marcaron el intento de resistir la caída con la lucha en las calles.

Entre fines de 1988 y los primeros meses de 1989 las expectativas de cambio social se depositaron en el terreno electoral, y mucho del conflicto se canalizó hacia allí. Durante 1990 fue clara la instauración hegemónica del neoliberalismo en la región, aunque todavía no se expresaba un desplome en la conflictividad social: la resistencia seguía presentándose como una opción. Eso cambió radicalmente durante los primeros años de la nueva década. ${ }^{36}$

En primer término, observemos quiénes fueron los sujetos claves de la conflictividad:

\footnotetext{
31 A fines de una redacción menos repetitiva, utilizamos "conflicto social" o "protesta" como sinónimos.

32 María Celia Cotarelo, "Conflicto social en Argentina entre 2002 y 2008", Actas XII Jornadas Interescuelas de Historia, Bariloche. UNCo. 2009.

33 Nicolás Iñigo Carrera y M. Cotarelo, "Algunos rasgos de la rebelión en Argentina 1993-2001", PIMSA 2004, Buenos Aires, PIMSA, 2004, 125-138.

${ }^{34}$ Ver Alfredo Pucciarelli (coord.), Los años de Alfonsín ¿El poder de la democracia o la democracia del poder?, Buenos Aires, Siglo XXI, 2006.

${ }^{35}$ G. Pérez Álvarez, Patagonia, conflictividad social y neoliberalismo 1990-2005, Buenos Aires, Imago Mundi, 2013; Horacio Ibarra y Carlos Hernández, Estado, Economía y Sociedad. Trelew y su hinterland: 1989-1999, Trelew, INSHIS-UNP, 2017.

${ }^{36}$ Ver G. Pérez Álvarez, "Conflictos sociales en el nordeste de Chubut: cambios y permanencias a través de veinte años de registro (1986-2005)", Estudios del Trabajo N52, Buenos Aires, ASET, 2016, http://www.scielo.org.ar/scielo.php?script=sci_arttext\&pid=S2545-77562016000200003.
} 
Cuadro No 1: Hechos de rebelión entre 1984 y 1990 en noreste de Chubut según sujeto ${ }^{37}$ que lo protagoniza.

\begin{tabular}{|c|c|c|c|c|c|c|c|c|c|c|}
\hline Año & $\begin{array}{l}\text { Asalariad } \\
\text { os }\end{array}$ & $\begin{array}{l}\text { Asalaria } \\
\text { d.+otros }\end{array}$ & $\begin{array}{l}\text { Estudia } \\
\text { ntes }\end{array}$ & $\begin{array}{l}\text { Peque- } \\
\text { ña burg. }\end{array}$ & $\begin{array}{l}\text { Vecinos } \\
\text { y pob. }\end{array}$ & $\begin{array}{l}\text { Desocup } \\
\text { ados }\end{array}$ & $\begin{array}{l}\text { Pobres/ } \\
\text { villeros }\end{array}$ & $\begin{array}{l}\text { Militant } \\
\text { es, dirig. }\end{array}$ & Otros & Total \\
\hline $\mathbf{1 9 8 4}$ & 137 & 2 & 8 & - & 2 & - & 2 & 11 & 15 & $\mathbf{1 7 7}$ \\
\hline $\mathbf{1 9 8 5}$ & 140 & 4 & 2 & 2 & 1 & - & 7 & 9 & 7 & $\mathbf{1 7 2}$ \\
\hline $\mathbf{1 9 8 6}$ & 119 & 5 & 4 & 3 & - & - & 3 & 4 & 3 & $\mathbf{1 4 1}$ \\
\hline $\mathbf{1 9 8 7}$ & 173 & 10 & 3 & 1 & 1 & - & 1 & 8 & - & 197 \\
\hline $\mathbf{1 9 8 8}$ & 166 & 7 & 7 & 5 & 2 & 1 & - & 8 & - & 196 \\
\hline $\mathbf{1 9 8 9}$ & 117 & 2 & - & 3 & - & - & 1 & 5 & 2 & $\mathbf{1 3 0}$ \\
\hline $\mathbf{1 9 9 0}$ & 74 & 12 & 11 & 2 & - & 3 & - & 1 & 2 & $\mathbf{1 0 5}$ \\
\hline Total & $\mathbf{9 2 6}$ & $\mathbf{4 2}$ & $\mathbf{3 5}$ & $\mathbf{1 6}$ & $\mathbf{6}$ & $\mathbf{4}$ & $\mathbf{1 4}$ & $\mathbf{4 6}$ & $\mathbf{2 9}$ & $\mathbf{1 1 1 8}$ \\
\hline $\mathbf{\%}$ & $\mathbf{8 3}$ & $\mathbf{3 , 7}$ & $\mathbf{3 , 1}$ & $\mathbf{1 , 4}$ & $\mathbf{0 , 5}$ & $\mathbf{0 , 3}$ & $\mathbf{1 , 2}$ & $\mathbf{4 , 1}$ & $\mathbf{2 , 6}$ & \\
\hline
\end{tabular}

Fuente: elaboración propia en base al registro de Diario Jornada.

A contramano de las interpretaciones mayoritarias, que sostenían una caída de los hechos protagonizados por los asalariados en los años '80, ellos son el sujeto fundamental de la conflictividad en la región. El abrumador $83 \%$ de los hechos fueron desarrollados por asalariados, subiendo esta proporción a $86,7 \%$ si se suman los protagonizados por asalariados y otros.

Son poco relevantes, en este período, los hechos protagonizados por desocupados. En los años trabajados esa situación aún no era una problemática para la clase obrera en la región; recién empezaba a serlo hacia 1990, y es allí cuando ya se destacan 3 hechos generados desde esa personificación social.

Sólo presentan una proporción importante el sujeto militantes y dirigentes y el estudiantil, ambas expresiones tradicionales de la conflictividad. Los distintos colectivos, que estudios como los de Jelin calificaban de "nuevos sujetos", representaban una ínfima proporción y por ello los agrupo en la categoría "otros". No son un factor explicativo clave, excepto en pocos años: por ejemplo en 1984, cuando los presos generaron diversas protestas, reclamando su libertad o mejores condiciones tras el fin de la dictadura.

Observemos qué sucede cuando se analizan los hechos protagonizados por asalariados ocupados, discriminándolos según sean de empleo estatal, privado o realizados en conjunto:

${ }^{37}$ Las categorías de sujetos incluidos en el cuadro son:

Asalariado - Asalariado y otros: asalariados más pequeña burguesía, estudiantes, patrones, propietarios, vecinos, usuarios, pobres, etc. - Estudiantil y comunidad educativa. - Pequeña burguesía: comerciantes, empresarios, propietarios de medios de transporte, vendedores ambulantes, productores agropecuarios, profesionales, ahorristas. - Vecinos y Pobladores. - Desocupados. - Pobres, villeros, sin techo, sin tierra. Militantes, dirigentes, funcionarios. - Otros: familiares de víctimas, familiares de detenidos, ecologistas, ex combatientes de Malvinas, madres de un barrio, hinchas de club de fútbol, presos, iglesias, pueblo. 
Cuadro $\mathrm{N}^{\mathrm{O}}$ 2: Hechos protagonizados por asalariados ocupados según éstos sean realizados por estatales, por privados o en conjunto, entre 1984 y 1990 en el noreste de Chubut.

\begin{tabular}{|c|r|r|r|r|}
\hline & \multicolumn{1}{|l|}{ Estatales } & \multicolumn{1}{|l|}{ Privados } & Conjunto & Total \\
\hline $\mathbf{1 9 8 4}$ & 41 & 89 & 7 & 137 \\
\hline $\mathbf{1 9 8 5}$ & 50 & 85 & 9 & 144 \\
\hline $\mathbf{1 9 8 6}$ & 39 & 76 & 9 & 124 \\
\hline $\mathbf{1 9 8 7}$ & 93 & 73 & 7 & 173 \\
\hline $\mathbf{1 9 8 8}$ & 109 & 49 & 8 & 166 \\
\hline $\mathbf{1 9 8 9}$ & 64 & 53 & - & 117 \\
\hline $\mathbf{1 9 9 0}$ & 56 & 18 & - & $\mathbf{7 4}$ \\
\hline Total & $\mathbf{4 5 2}$ & $\mathbf{4 4 3}$ & $\mathbf{4 0}$ & $\mathbf{9 3 5}$ \\
\hline \% s/Asal. & $\mathbf{4 8 , 3}$ & $\mathbf{4 7 , 4}$ & $\mathbf{4 , 3}$ & $\mathbf{9 3 5}$ \\
\hline \% s/Total & $\mathbf{4 0 , 4}$ & $\mathbf{3 9 , 6}$ & $\mathbf{3 , 6}$ & $\mathbf{1 1 1 8}$ \\
\hline
\end{tabular}

Fuente: elaboración propia en base al registro de Diario Jornada.

Surge un dato central: la escasa cantidad de hechos protagonizados por el conjunto de los asalariados. La división entre trabajadores estatales y privados se profundiza en la región por el rol que tuvo el estado en su desarrollo, tanto en el ámbito estatal como en el formalmente privado. El reclamo de los "privados" era que el estado provincial ocupase el rol que antes cumplía el nacional, subsidiando las inversiones de empresas privadas. Por su parte los estatales demandaban que esos recursos se destinasen a sus salarios. Esa división se hizo más patente en el momento de quiebre, 1989-1990: no hay ningún hecho conjunto en esos años, generando, desde el poder político y económico, la fractura de la clase.

Se hace evidente el alto grado de conflictividad que exhibieron los trabajadores de ambos sectores hasta 1989. En los privados puede observarse una caída abrupta, ya visible en 1990. Entre los estatales fue muy alto el número de conflictos entre 1986 y 1990, y en especial durante 1987-88, cuando se profundizaron los recortes al gasto público. hechos:

Veamos cuáles fueron las formas organizativas desde las que se convocaron estos

Cuadro No 3: Hechos entre 1984 y 1990 en el noreste de Chubut según organización ${ }^{38}$ convocante.

\begin{tabular}{|l|l|l|l|l|l|l|l|l|l|}
\hline & $\begin{array}{l}\text { Sindi } \\
\text { cal }\end{array}$ & $\begin{array}{l}\text { Sindical } \\
\text { y otro }\end{array}$ & $\begin{array}{l}\text { Multi } \\
\text { sect. }\end{array}$ & $\begin{array}{l}\text { Empresa } \\
\text { ria }\end{array}$ & $\begin{array}{l}\text { Estu } \\
\text { diantil }\end{array}$ & $\begin{array}{l}\text { Desoc } \\
\text { upados }\end{array}$ & $\begin{array}{l}\text { Partidos y } \\
\text { organiz. }\end{array}$ & Otros & Total \\
\hline $\mathbf{1 9 8 4}$ & 129 & 7 & 4 & 1 & 8 & - & 11 & 17 & $\mathbf{1 7 7}$ \\
\hline $\mathbf{1 9 8 5}$ & 141 & 5 & - & 3 & 4 & - & 9 & 10 & $\mathbf{1 7 2}$ \\
\hline $\mathbf{1 9 8 6}$ & 115 & 7 & 1 & 3 & 4 & - & 4 & 7 & $\mathbf{1 4 1}$ \\
\hline $\mathbf{1 9 8 7}$ & 172 & 5 & 6 & 1 & 3 & - & 7 & 3 & $\mathbf{1 9 7}$ \\
\hline $\mathbf{1 9 8 8}$ & 166 & 2 & 7 & 5 & 6 & 1 & 7 & 2 & $\mathbf{1 9 6}$ \\
\hline $\mathbf{1 9 8 9}$ & 118 & 1 & - & 3 & - & - & 5 & 3 & $\mathbf{1 3 0}$ \\
\hline $\mathbf{1 9 9 0}$ & 74 & 3 & 8 & 2 & 4 & 3 & 1 & 10 & $\mathbf{1 0 5}$ \\
\hline Total & $\mathbf{9 1 5}$ & $\mathbf{3 0}$ & $\mathbf{2 6}$ & $\mathbf{1 8}$ & $\mathbf{2 9}$ & $\mathbf{4}$ & $\mathbf{4 4}$ & $\mathbf{5 2}$ & $\mathbf{1 1 1 8}$ \\
\hline $\mathbf{0}$ & $\mathbf{8 1 , 8}$ & $\mathbf{2 , 7}$ & $\mathbf{2 , 3}$ & $\mathbf{1 , 6}$ & $\mathbf{2 , 6}$ & $\mathbf{0 , 3}$ & $\mathbf{3 , 9}$ & $\mathbf{4 , 6}$ & \\
\hline
\end{tabular}

Fuente: elaboración propia en base al registro de Diario Jornada.

\footnotetext{
${ }^{38}$ Las categorías utilizadas son las siguientes: Sindical: incluye las instancias de organización sindical nacional, seccional, comisiones internas, delegados, etc. Sindical y otros: sindical y partidos políticos, y grupos de DDHH, y organizaciones vecinales, de pequeños propietarios, estudiantiles, multisectoriales, de desocupados, de empresarios. Multisectorial - Empresaria: de empresarios, profesionales y gubernamental. Estudiantil: incluye de estudiantes y comunidad educativa y estudiantes y grupos políticos. Desocupados. Partidos y organizaciones políticas. Otros: espontánea, vecinal, auto convocada, religiosa, de DDHH, de pequeños propietarios, familiares de víctimas, ecologistas, consumidores, iglesias, ecologistas, pueblos originarios, policías, guardia cárceles, etc.
} 
El dato insoslayable es la centralidad de la organización sindical. En segundo término fue importante el peso de partidos y organizaciones políticas: se explica por la disputa democrática y el desarrollo de fuerzas de izquierda en la región (que se perdería hacía 1990). ${ }^{39}$ La supuesta pérdida de relevancia de los articuladores tradicionales de la conflictividad social queda evidentemente descartada por estos datos.

En 1984-85 las protestas de presos, y algunos hechos protagonizados por fuerzas represivas (acuartelamientos), no tuvieron convocatoria clara y aparecían con un carácter "espontáneo". También fueron relevantes los hechos generados por organismos de derechos humanos.

La siguiente pregunta hace a observar cuáles fueron las formas que tomó la conflictividad social. Durante años se afirmó que se había producido un "cambio de repertorio" en los instrumentos de protesta "clásicos", donde perdería peso la huelga (formato que sólo puede ser desarrollado por asalariados ocupados) y las acciones tradicionales de la clase obrera:

Cuadro N 4: Hechos entre 1984 y 1990 en noreste de Chubut según forma o instrumento ${ }^{40}$ utilizado

\begin{tabular}{|c|c|c|c|c|c|c|c|c|c|}
\hline Año/forma & Manifestación & Cortes & Huelga & Ocupación & Saqueo & Ataque & $\begin{array}{l}\text { Lock- } \\
\text { out }\end{array}$ & Otros & Total \\
\hline 1984 & 78 & - & 78 & 7 & - & 2 & - & 12 & 177 \\
\hline 1985 & 85 & 1 & 70 & 8 & - & 3 & 1 & 4 & 172 \\
\hline 1986 & 58 & 2 & 71 & 2 & - & - & 1 & 7 & 141 \\
\hline 1987 & 99 & - & 70 & 10 & - & 5 & - & 13 & 197 \\
\hline 1988 & 99 & 6 & 75 & 6 & - & 2 & 2 & 6 & 196 \\
\hline 1989 & 58 & 1 & 64 & 1 & - & 1 & & 5 & 130 \\
\hline 1990 & 47 & 1 & 36 & 9 & - & 6 & - & 6 & 105 \\
\hline Total & 524 & 11 & 464 & 43 & - & 19 & 4 & 53 & 1118 \\
\hline$\%$ & 46,9 & 1 & 41,5 & 3,9 & - & 1,7 & 0,3 & 4,7 & \\
\hline
\end{tabular}

Fuente: elaboración propia en base al registro de Diario Jornada.

La protesta callejera (manifestaciones y cortes) agruparon el $47,9 \%$ de los hechos y las huelgas mantuvieron una importancia indiscutible, explicando el 41,5\% de las acciones. La tan mentada caída de las formas tradicionales de conflicto no parece demostrarse cuando se recopilan datos concretos: sumando manifestaciones, cortes, huelgas y ocupaciones, todos formatos "clásicos", se agrupan el 93,3\% de los hechos.

${ }^{39}$ G. Pérez Álvarez, "Experiencia obrera, construcciones sindicales y organizaciones políticas de la clase obrera. Los trabajadores de la Patagonia argentina durante la década del '80", Historia Actual Online $\mathrm{N}^{\circ} 37$, Cádiz, Universidad de Cádiz, 2015, 53-68.

${ }^{40}$ Las categorías utilizadas son:

Manifestación: incluye marcha, concentraciones, carpas, escraches, radios abiertas, ollas populares, exhibición artística y festivales, abrazo a edificio, misas, asambleas públicas, caravanas de vehículos, clases públicas, batucada, cacerolazo, tractorazo, ayuno colectivo, vigilia. Cortes: incluye corte de ruta y corte de calle. Ocupaciones: de lugares de trabajo, facultades, escuelas, edificios públicos, bancos, viviendas, terrenos, edificios abandonados, empresas privatizadas, locales sindicales, plazas, etc. Ataques: apedreos e incendios de edificios públicos, bancos, sedes de empresas, medios de transporte, locales partidarios o sindicales. Otros: huelga de hambre, motín carcelario, resistencia a desalojo de vivienda o terreno, encadenamiento, trabajo a desgano, acuartelamiento, cerco a supermercado, cerco a legislatura, etc. 


\section{Los metalúrgicos}

Desde inicios de 1984 comienza la disputa por la normalización sindical. En febrero se constituyó la agrupación metalúrgica del Chubut, corriente interna de la UOM que respondía a la dirección oficial del sindicato a nivel nacional ${ }^{41}$. En su presentación pública expresaban su reclamo por una ley de reordenamiento sindical que garantizase la participación de los trabajadores, por la vigencia de la ley 14.250 de convenios colectivos de trabajo y por la recuperación de la obra social sindical. Esas, y otras demandas similares, serán comunes a las diferentes líneas internas.

En marzo se produjo un reclamo por aumento salarial: los obreros ejecutaron un "trabajo a reglamento", que provocó una relevante merma productiva ${ }^{42}$. El delegado normalizador de la UOM, Vicente Jara, rechazó esa intimación, denunciando que la delegación laboral tomó la medida siguiendo los dichos de la empresa, sin buscar otras fuentes y sin realizar ninguna inspección en la planta fabril.

Los obreros exigían la recuperación del nivel salarial deteriorado desde 1976, año de inicio de la dictadura recientemente finalizada. La lista opositora de la UOM convocó, como agrupación "Rafael Uribe" ${ }^{43}$, a una asamblea a realizarse el 12 de agosto, para conformar la nómina de candidatos. Sostienen que adherían a los paros nacionales convocados "porque somos conscientes de las necesidades de nuestros compañeros", aunque también afirman que "no es justo que estemos presionando tanto como para que demos cabida a muchos gorilas que agazapados en la oscuridad esperan que fracase el actual gobierno" ${ }^{44}$.

El 8 de agosto se publicó en tapa de los diarios regionales la convocatoria al acto por el décimo aniversario de la primera colada de aluminio en Aluar. Madanes, dueño de la compañía, destacó que las grandes empresas habían sobrevivido, y hasta salieron fortalecidas, de la dictadura $^{45}$. El 23 y 24 de agosto se produjo una huelga de la UOM, que fue acatada en la región con adhesión total, aunque manteniendo los "servicios esenciales".

La columna "Panorama Gremial", en el Diario Jornada del 12 de octubre, destacaba la preocupación de la línea "tradicional" del sindicalismo, por las elecciones en la UOM local, donde parecía difícil la victoria oficialista. La oposición tenía un peso clave en Aluar,

${ }^{41}$ Sobre esta línea, quizás la más tradicional y colaboracionista del sindicalismo argentino, ver Santiago Senén González y Fabián Bosoer, El hombre de hierro. Vandor, Rucci, Miguel, Brunelli, Buenos Aires, Corregidor, 1993; Darío Dawyd, "El nuevo autoritarismo burocrático y el sindicalismo peronista. Análisis de la 'participación' junto al gobierno militar de Onganía en la Argentina de los años sesenta: del 'nuevo orden social' al 'Cordobazo'", Confluenze. Rivista di Studi Iberoamericani, Italia, Università di Bologna, 2012; Mauricio Correa, "El fracaso de la concepción sindical vandorista de la UOM San Nicolás en el conflicto por la privatización de SOMISA", Historia Regional N²4, Villa Constitución, ISP №3, 2006, 65-86

${ }^{42}$ Diario Jornada, edición del 27/3/1984; p. 2.

${ }^{43}$ Nombre de un militante obrero de Aluar, que había muerto pocos meses antes.

${ }^{44}$ Diario Jornada, edición del 27/4/1984; p. 2.

45 Esta declaración es interesante para aportar a la discusión sobre la noción de "des-industrialización", especialmente utilizada en Argentina. Ver el debate volcado en la Revista de Estudios Sociales y Marítimos $\mathrm{N}^{\circ}$ 5, UNMdP, año 2013. Juan Grigera, "El concepto de desindustrialización como peculiaridad argentina", 187-195; G. Pérez Álvarez, "Una discusión con el concepto de 'des industrialización' desde el caso del noreste de Chubut", 175-185; en http://ri.conicet.gov.ar/bitstream/handle/11336/3258/REMS_N_5-6__Debate.pdf?sequence=1\&isAllowed=y. 
caracterizándola como una "coalición de izquierda", con integrantes del Partido Comunista, el Partido Socialista Auténtico y el Partido Socialista Democrático.

Días después varios integrantes de la "Rafael Uribe" expresaron, públicamente, que su sector no era "izquierdista": "La composición de nuestra agrupación en forma mayoritaria es peronista, como es normal en el movimiento obrero, pero se permite la participación de compañeros de distinta ideología en base a los objetivos comunes". Se sostuvo que la encabezaba un "peronista independiente", como Carlos Rodríguez, proponiendo elegir delegados por secciones en las fábricas grandes y en todos los talleres, oponiéndose al modelo de lista completa de la "burocracia sindical" y llamando a construir una CGT combativa "donde tengan participación directa los compañeros elegidos por las bases"46. La evidente preocupación por evitar el "estigma" de "izquierdistas", muestra parte de las consecuencias de la dictadura.

En las elecciones derrotaron ampliamente al oficialismo, ganando por 501 votos a 222; su victoria fue arrasadora en Aluar, por 458 a 95. Desde inicios de 1985 comenzaron con las elecciones de delegados por sección o taller, aún ante las denuncias de "fraude" del oficialismo a nivel nacional (ahora opositor en lo regional). La conducción de la UOM local jugó un rol clave en la renovación de la CGT del noreste de Chubut. El 30 de agosto de ese año se produjo otro paro nacional de la CGT que tuvo a la UOM como actor central.

En diciembre, y en el marco de esta serie de huelgas y movilizaciones por aumento salarial, tuvo lugar una acción realmente singular y relevante: la nueva conducción sindical planteó en asamblea su protesta por las peligrosas condiciones ambientales que se vivían en Aluar "una vieja reivindicación que anhelan los metalúrgicos de la zona desde el inicio de las actividades de la única fábrica de aluminio primario del país"47. La asamblea concluyó con una gran movilización por las calles de Madryn, con diversas reivindicaciones en materia de higiene y salubridad en el trabajo.

El dirigente Carlos Rodríguez destacaba que "Después de tener dos expedientes del Departamento de Higiene y Salubridad del Ministerio de Trabajo desfavorables, ahora confiados en esta incipiente democracia esperan conseguir una justa inspección donde puedan participar todas las partes involucradas, no como en ocasiones anteriores en que sólo participó la empresa y alguno que otro trabajador. Ahora queremos conseguir que participen trabajadores, directivos del gremio, la empresa, técnicos del Ministerio de Trabajo y técnicos de nuestro gremio para que todas las partes puedan opinar como es normal en un sistema democrático" ${ }^{48}$.

La acumulación de fuerzas había hecho posible la impugnación al modelo por el cual la empresa transformaba la vida de "sus obreros" en mercancía descartable, donde el sindicato debía limitarse a reclamar mejores salarios, sin cuestionar el derecho de la patronal a gestionar el uso de los cuerpos obreros como si fuesen cosas. Sin embargo, esta acción quedó aislada. Luego se sucedieron duras derrotas, que lograron extirpar estas preocupaciones claves del radar de la actividad sindical.

Durante 1986 se vivió una situación de crisis laboral en Madryn, con despidos en la construcción y en las empresas tercerizadas o subsidiarias de Aluar. La UOM apoyó el reclamo

\footnotetext{
${ }^{46}$ Diario Jornada, edición del 18/10/1984; p.8.

${ }^{47}$ Diario Jornada, edición del 3/12/1985; p. 2.

${ }^{48}$ Diario Jornada, edición del 3/12/1985; p. 2.
} 
y adhirió a una importante huelga general solidaria, de gran impacto en Puerto Madryn: el conflicto se extendió por varios días, con marchas y asambleas y conquistando muchos de los reclamos obreros.

En mayo de 1987 la "Rafael Uribe" hizo un balance de su tercer año de existencia, el segundo a cargo de la conducción de la UOM regional. Remarcaron la importancia de sostener conducciones pluralistas que no estén al servicio de un partido político, planteando la necesidad de la unidad de los trabajadores y de sostener la democracia sindical. Reconocían que estaban atravesado discusiones y problemas dentro de la estructura sindical, especialmente por sostener estas posturas en la práctica.

Justamente durante ese año, uno antes de las nuevas elecciones, empezaron a profundizarse las internas en la conducción, por las posturas más negociadoras de Carlos Rodríguez y algunos integrantes de la lista (ligados al PJ y el PSA). En agosto visitó la zona el dirigente nacional de la UOM, Lorenzo Miguel, quien calificó como "amigo" al secretario general local. En noviembre hubo un paro nacional de la CGT: la nueva postura, más conciliadora, de la UOM se evidenció al ser uno de los sindicatos que repudió los ataques a firmas que no quisieron cerrar sus puertas (Rodríguez los denominó "desbordes"). La huelga en Madryn tuvo una marcha que no superó las cien personas, mucho menor a lo que antes reunía sólo la UOM.

Durante 1988 toda la actividad militante de estos obreros se dirigió a la nueva elección sindical. Se profundizó la disputa en la "Rafael Uribe": en elección interna los dirigentes Rodríguez y Giussi (PJ y PSA) fueron derrotados, pero ambos afirmaron que ellos eran los legítimos representantes de la lista. Con la "Uribe" fragmentada, y en plena pelea fraccional, las elecciones lograron ser ganadas por el oficialismo nacional.

Al comenzar 1989 se produjo un accidente en Aluar, en el cual un trabajador murió (Ricardo Hlywy), otro sufrió heridas graves y hubo ocho heridos leves. No se conocieron las causas del hecho, uno de tantos que costaron vidas en Aluar. La UOM local no expresó ninguna postura, ni ante este hecho ni durante todo 1989.

Se cerraba así un ciclo, con un paralelo muy similar en la AOT regional, donde ganaron la conducción sindical listas que se definían como pluralistas y combativas, siendo reemplazadas por las conducciones tradicionales en la siguiente elección. En la UOM fue un proceso de importante movilización política y social, que luego no se tradujo en la transformación del sindicato. Si bien en los primeros años plantearon cambios hacia una mayor democracia interna y presencia en las calles, de a poco la nueva dirección se fue apartando de ese modelo.

\section{Los textiles}

Como ya lo destaqué en el apartado previo, su proceso fue similar al de los metalúrgicos. Tras el regreso al régimen constitucional entre los textiles se evidenció el surgimiento de nuevos agrupamientos. Las fuerzas que se habían acumulado avanzaban en la búsqueda de nuevas conquistas y derechos. La capacidad de movilización que expresaban estos obreros evidencia la necesidad de poner en cuestión la afirmación taxativa de que emergían de una profunda derrota. Aún más claramente pone en jaque ese sentido común dominante que sostenía la pérdida de relevancia del sujeto obrero para analizar la conflictividad social. 
En la AOT se comenzó a debatir la conformación de una lista que planteara la disputa contra la conducción sindical proveniente de la dictadura ${ }^{49}$. La agrupación textil más potente, en repercusión pública y número de integrantes, fue la denominada " 1 ” de Mayo de 1853" 50 , que en 1985 logró conformar una amplia alianza para derrotar a la lista de Luis Del Río, quién había dirigido la AOT regional durante la dictadura.

Veamos, casi a modo de muestra, una descripción de algunos conflictos y pronunciamientos públicos vinculados a la disputa sindical en la AOT durante los primeros tres meses de 1984, recién retomado el incipiente régimen constitucional. El 3 de enero la agrupación gremial "Felipe Vallese", de Rawson, denunciaba "la falta de consideración del gorilaje oligárquico" ${ }^{51}$, planteando que la AOT "no encara la cuestión con la energía con que se tiene que tomar este tipo de luchas reivindicatorias obreras". Además, afirmaban que Mulcosur, empresa textil de la ciudad de Rawson, hizo trabajar todos los feriados de diciembre del '83.

El 7 de enero la "1 de mayo..." denunció una "oleada de despidos masivos en una industria textil de Trelew" ${ }^{15}$. Sucedía en Modecraft, "reconocida por todos los textiles como una de las empresas de trato más inhumano y antisocial". Las obreras despedidas Mabel Ibañez y Dalia Hidalgo sostenían que "Mientras aducen falta de trabajo, exigen más producción y pagan más horas extras". Varias de ellas denunciaron la suciedad y malas condiciones de trabajo; Liliana Bahamonde declaraba haberse desmayado a causa del calor y humo constante en el interior de la planta. Fueron acompañadas por los dirigentes de la "10 de mayo", René Perez, Carlos Hernández, Luis Gualdieri y Eduardo Rivera ${ }^{53}$, y se reunieron con el gobernador de la provincia, planteando la preocupación por la situación general en el Parque Industrial de Trelew. Manifiestan que muchos de los despidos, en Modecraft y otras plantas, fueron por motivos gremiales y/o políticos.

Mulcosur publicó una solicitada destacando que empleaba alrededor de 200 personas "remuneradas de acuerdo con las escalas más elevadas que rigen para la actividad". Elogiaron la labor de los sindicatos "oficiales", criticando a los grupos "extraños al ámbito laboral y muchas

\footnotetext{
49 Sobre la historia de la AOT, ver Marcos Schiavi, "La Asociación Obrera Textil (1945-1955): La dinámica sindical en los sindicatos peronistas", Anuario IEHS 28, Tandil, UNCPBA, 2013, 313-327; M. Schiavi, "Conflicto y organización sindical en los orígenes del peronismo: la conformación de la Asociación Obrera Textil", Archivos de historia del movimiento obrero y la izquierda n², Buenos Aires, ProHMOI, 2013, 9-32.

${ }^{50}$ El singular nombre de la agrupación era una de las expresiones de la amplia y compleja unidad que allí se intentaba gestar. Convergían militantes ligados al comunismo y el peronismo combativo (grupos de donde provenía el " $1^{\circ}$ de mayo"), con sectores cuyo eje de reivindicación era el recuperado constitucionalismo y la demanda de democratización al interior de los sindicatos (de allí el "1853", fecha de promulgación de la constitución argentina). Es preciso destacar que, en las escuelas, durante la dictadura, la referencia al $1^{\circ}$ de mayo se centraba en el aniversario de la promulgación de la constitución nacional de 1853.

${ }^{51}$ Diario Jornada, edición del 3/1/1984; p. 6. El nombre Felipe Vallese, rememora al obrero metalúrgico y dirigente de la Juventud Peronista secuestrado y desaparecido el 23 de agosto de 1962, durante el gobierno de facto de José María Guido. Remite a una identidad política propia del peronismo "de izquierda" o combativo, como también lo hace la referencia a un "gorilaje oligárquico". Ver al respecto Carlos Altamirano, Peronismo y cultura de izquierda, Buenos Aires, Siglo XXI, 2011; Julieta Bartoletti, "Dilemas de la Izquierda Peronista", Actas III Jornadas de Sociología de la UNLP, La Plata, UNLP, 2003, http://www.memoria.fahce.unlp.edu.ar/trab_eventos/ev.6847/ev.6847.pdf.

${ }^{52}$ Diario Jornada, edición del 9/1/1984; p. 20.

${ }^{53}$ Diario Jornada, edición del 10/1/1984; p. 6.
} 
veces contrarios no sólo a la moral sino a la ley misma". Hacían referencia allí a la nota crítica de la Felipe Vallese, que tenía su núcleo militante en dicha planta.

El dirigente Del Río acusó a "cierto grupúsculo gremial local", sosteniendo que era una mentira decir que él no defendía a los trabajadores despedidos, y difundiendo logros salariales y de condiciones de seguridad e higiene. ${ }^{54} \mathrm{El} 6$ de febrero se publicó un reclamo de elecciones en la AOT efectuado por la "1 de mayo...", exigiendo la reincorporación de los cesanteados, la lucha por un salario de 8 mil pesos por 8 horas de trabajo y la recuperación de la AOT para los trabajadores. Por su parte la Felipe Vallese, desmentía lo publicitado por Del Río sobre supuestos incrementos de los sueldos en Mulcosur.

Ese mes se conformó un nuevo agrupamiento textil, denominado Juan Manuel de Rosas $^{55}$. Su objetivo era "lograr la independencia económica, gremial y la democratización del Sindicato AOT seccional Trelew". Integraban el grupo Miguel Angel Llouful (Soltex), Julio Arancibia (Surjet), Luis Lastra (Roma), Haydeé Pradena (Briozzo).

Los integrantes de la "1 de mayo..." exigieron, nuevamente, aumento salarial y elecciones en la AOT. Sostenían que junto a la Felipe Vallese, de Rawson, y a obreros de Madryn estaban elaborando una lista común para las elecciones sindicales. Pero, en verdad, el eje de la nota pública era desmentir las versiones que indicaban que dicha agrupación pertenecía al PC. Luis Gualdieri, Daniel Real, Cesar Ramiro Mella y Oscar Secco, manifestaron que la conducción tenía "tres compañeros justicialistas, uno de la $\mathrm{DC}^{56}$ y uno del PC" y calificaron de "malignas" esas versiones. Vemos aquí el mismo temor de los integrantes de la "Rafael Uribe", en no ser identificados como "izquierdistas" o "del PC".

En la textil Tendlarz se inició en marzo una medida de quite de colaboración, bajando los niveles productivos para reclamar una mejora salarial. Además, se negaron a realizar horas extras, denunciando que sólo trabajando 12 horas diarias podían llegar a un salario digno. Al otro día Del Río salió a desmentir que hubiese conflictos en fábricas del parque: según él, apenas hubo una solicitud satisfactoriamente respondida por la patronal. Sostuvo que, a través de negociaciones, se consiguieron aumentos en Matepa, Foderami, Surjet, Oceanic, Punilla y Surlon, y que, exceptuando a Aluar, "los mejores sueldos que se pagan en la zona son para los textiles".

La agrupación Juan Manuel de Rosas también reclamaba mejores salarios, centrando su exigencia en no tener que trabajar más de 8 horas. Afirmaban que los obreros debían conquistar su derecho a poder pasar tiempo con su familia e ilustrarse.

Por su parte la "1 de mayo" informó, a fines de marzo, que desde el 9 de abril atendería todos los reclamos en la casa parroquial de la Iglesia María Auxiliadora, en el horario de 19 a 20 horas. Declaraban que "tenemos que luchar para que en 8 horas de trabajo logremos un salario con el que podamos mantener dignamente a nuestras familias; esto únicamente lo

\footnotetext{
${ }^{54}$ Diario Jornada, edición del 22/1/1984; p. 8.

55 Gobernador de la provincia de Buenos Aires entre 1829 y 1832, y nuevamente entre 1835 y 1853 , seguramente una de las figuras políticas más relevantes de la historia argentina. Su reivindicación expresa una identidad peronista conservadora, en general con fuertes rasgos nacionalistas y tradicionales. Ver Julio Stortini, "Rosas a consideración. Historia y memoria durante el menemismo", Actas XI Jornadas Interescuelas/Departamentos de Historia, San Miguel, Universidad de Tucumán, 2007; Raúl Fradkin y Jorge Gelman, Juan Manuel de Rosas. La construcción de un liderazgo político, Buenos Aires, Edhasa, 2015.

${ }^{56}$ Democracia Cristiana.
} 
conseguiremos teniendo al frente de nuestro sindicato una conducción combativa y representativa de los reales intereses obreros"..$^{7}$

Podría seguirse esa descripción de manera mucho más densa, pero me detengo aquí: por razones de espacio no es posible volcar más elementos en este artículo y, a su vez, entiendo que la muestra evidencia la profusa actividad que desarrollaban los agrupamientos textiles que construirían la lista sindical opositora a la conducción tradicional.

El triunfo de la nueva propuesta sindical no consiguió generar una transformación del sindicato y su dinámica de funcionamiento. Si bien en los primeros años se plantearon cambios hacia una mayor democracia interna y presencia en las calles, de a poco la nueva dirección textil se fue apartando de ese modelo. La nueva conducción se fue adaptando a las características de la dirigencia nacional. En las entrevistas los trabajadores destacaron la importancia que tuvo la presión a través del ahogo financiero, en cada ocasión en que la regional proponía medidas en las calles. El proyecto de la "10 de mayo" finalmente se fracturó, conformándose agrupaciones identificadas con los diversos partidos políticos. ${ }^{58}$

Hacia 1986-87 comenzaba a surgir una mayor conflictividad laboral en la región, debido a los recortes de los beneficios ${ }^{59}$. Esto impactó en el parque textil de Trelew, donde los cierres de fábricas y los despidos comenzaron a ser noticias diarias. A inicios de 1987 la textil Gebco anunció su quiebra y ante ello los obreros ocuparon la fábrica. Tras una toma de fábrica de más de 40 días, la dirigencia sindical anunció que se había conseguido "arrancarle a la patronal el 80\% de las indemnizaciones" y manifestaron su desacuerdo "con quienes quieren utilizar esta lucha con fines sectarios y divisionistas" ${ }^{60}$. No se había logrado evitar el cierre de la planta y ni siquiera se consiguió el pago de lo que debía abonarse legalmente; además los dirigentes atacaban a quienes proponían otra estrategia para dar la lucha. Se observa cómo la presencia de una mayor conflictividad no se traducía en un cambio de la perspectiva.

Los trabajadores de la región se encontraban ante un nuevo marco. Su historia de luchas pasaba por el reclamo de mejores condiciones laborales y aumento salarial; pero no tenían las herramientas para saber cómo actuar ante una situación donde las empresas no les querían comprar su fuerza de trabajo. Ya no se trataba de pelear por mejoras en el marco del mismo proyecto de los sectores dominantes: necesitaban enfrentarse con el programa que se les imponía. Era necesario un proyecto alternativo al del poder y para ello no era suficiente una conciencia limitada a lo corporativo.

El final de los '80 se constituyó en una bisagra histórica; en especial el año 1989 fue un punto de quiebre a nivel nacional. La hiperinflación y la revuelta ${ }^{61}$, la caída de Alfonsín y la asunción de Menem, generaron las condiciones para la hegemonía neoliberal ${ }^{62}$. En la región se

\footnotetext{
${ }^{57}$ Diario Jornada, edición del 30/3/1984; p. 7.

${ }^{58}$ G. Pérez Álvarez, "'Con hilos rotos vamos tejiendo otra historia' Lucha y experiencia obrera en el parque textil de Trelew", Sociohistórica No 27, La Plata, FAHCE-UNLP, 2011, 13-39.

59 Horacio Ibarra, Patagonia Sur. La construcción interrumpida de un proceso de desarrollo regional, Trelew, UNPSJB, mimeo, 1997.

60 Diario Jornada, edición del 29/4/1987, p. 8. La dirigencia enfrentaba los pronunciamientos de las agrupaciones textiles que habían cuestionado la falta de profundización de la lucha.

${ }^{61}$ Ver Nicolás Iñigo Carrera y otros, "La revuelta. Argentina 1989/90"; en PIMSA DT N ${ }^{o}$, Buenos Aires, PIMSA, 1995.

${ }^{62}$ Ver Bonnet, op. cit.
} 
aceleró la caída del polo desarrollista: se produjeron despidos masivos entre los textiles y otras actividades.

1989 fue un punto de quiebre para las construcciones sindicales de los trabajadores. En los primeros conflictos que se desarrollaron durante ese año se expresó la fuerza que habían construido varias organizaciones de izquierda. Dicha fortaleza se evidenció en que lograron ganar algunas asambleas en la AOT, derrotando a la conducción sindical que buscaba evitar los conflictos.

Sin embargo, esas victorias fueron coyunturales y no lograron expresarse más allá de momentos de auge y de esas instancias de participación colectiva. Luego se profundizó el ataque contra esos sectores. A la vez se evidenció la dificultad de los grupos opositores para construir un proyecto político-sindical alternativo. La derrota de la estrategia que planteaba la organización independiente de la clase obrera, derrota que se había construido a lo largo de los últimos años, ahora sí parecía realizada ${ }^{63}$.

Con la promoción industrial suspendida, el parque industrial de Trelew aceleró su crisis en 1990. Según la AOT el 90\% de las plantas registraba una caída de su producción, con despidos de personal y corte de cadenas de pago; se sucedieron diversos conflictos, sin articular los reclamos entre sí ni con otras fracciones obreras. Recién el 21 de marzo se produjo una movilización, pero sólo de trabajadores estatales, cuando a nivel nacional se realizaba la primera marcha contra el plan económico de Menem, convocada por la CGT "Azopardo". ${ }^{64}$ No hubo acciones en común de los sindicatos de trabajadores privados.

Esa división volvió a expresarse hacia fines de abril, cuando parte de los sindicatos del sector privado conformaron la CGT "regional noreste", alineada con la CGT "San Martín", el mismo día que en Rawson se movilizaron 2500 estatales, demandando mejores salarios. La fractura entre estas fracciones obreras se expresó durante el largo conflicto conocido como "Chubutazo" ${ }^{65}$; el mismo fue protagonizado por los estatales y generó la caída del gobernador Perl y su reemplazo por el vicegobernador Cosentino.

Tras este cambio en las alturas el proceso de lucha popular se agotó, pese a que en diciembre se anunció otra rebaja en los aranceles de importación que provocó el cierre definitivo de la etapa de esplendor del parque industrial local.

\section{Reflexiones finales}

En este artículo debatí con las posturas más difundidas acerca de la dinámica conflictual en la Argentina reciente; los resultados expuestos se oponen a quienes sostenían

\footnotetext{
${ }^{63}$ Pablo Pozzi y Alejandro Schneider, op.cit.

${ }^{64}$ La CGT se había fracturado según su alineamiento con el gobierno de Menem. La CGT "Azopardo" se oponía, al menos parcialmente, al proyecto neoliberal y era dirigida por Saúl Ubaldini; la CGT "San Martín” apoyaba a Menem y su secretario general era Guerino Andreoni. Sobre estas rupturas y el accionar de la CGT en torno a la conflictividad social, ver un debate en estos dos artículos: Nicolás Iñigo Carrera, "La huelga general como indicador de momentos de ascenso y descenso en la lucha de la clase obrera. Argentina 19842002"; Adrián Piva, "El desacople entre los ciclos del conflicto obrero y la acción de las cúpulas sindicales en Argentina (1989-2001)", ambos en Actas XII Jornadas Interesc. de Hist., Bariloche, UNCo, en CD.

65 María Paniquelli y Bruno Sancci, El Chubutazo: octubre de 1990, Buenos Aires, De los cuatro vientos, 2006; G. Pérez Álvarez, "Organizaciones y propuestas políticas en el conflicto social del noreste de Chubut 1990-1991", Actas IV Jornadas Latinoamericanas Hacer La Historia, La Pampa, UNLPampa, 2006, en CD.
} 
que la clase obrera había dejado de ser el sujeto fundamental del conflicto, así como los sindicatos y sus formas tradicionales de lucha habrían perdido centralidad. Esa mirada le quitaba legitimidad a las luchas de los trabajadores, debilitando a una clase obrera que ya emergía sumamente golpeada de la cruel represión dictatorial. La ofensiva fue exitosa: durante años la amplia mayoría de la academia argentina sostuvo estas opiniones, pese a que no se sustentaban en datos empíricos. Ese discurso hegemónico fue parte de la dinámica de pérdida de fuerza social de la clase obrera, que continuo durante los años ' 80 y se evidenció en la profunda derrota sufrida al iniciarse la década del ' 90.

Para una clase que provenía de la experiencia dictatorial, golpeada por la pérdida de sus mejores cuadros, esa postura llegaba a transformarse en un discurso que funcionaba a modo de sentido común. Si a eso le sumamos una región, como la analizada, donde la caída de industrias y puestos de trabajo se hizo noticia recurrente desde 1986, la suposición de que encontraríamos una clase obrera poco dinámica, y cuyo peso en la conflictividad tendería a perderse, parecería casi una obviedad.

Nada más alejado de lo aquí expuesto. Encontramos una clase obrera que fue el factor clave del conflicto, desde sus organizaciones tradicionales (sindicatos y partidos) y con sus formas clásicas de lucha (huelgas, manifestaciones, ocupaciones). Sólo un aspecto de estos discursos se observó como realidad en la investigación: la defensa de una perspectiva casi únicamente corporativa en los reclamos obreros. Como lo expuse esto siempre se encontrará cuando se restringe la observación al aparato institucional-sindical.

El enfoque aquí propuesto, que postula la necesidad de observar las luchas como el referencial concreto, muestra que también aparece otra estrategia en el movimiento obrero: la de construir un proyecto autónomo, con independencia de clase, que integre sus diversas fracciones y quiebre los límites del corporativismo. Esa propuesta se expresó en algunas luchas y en la conformación de agrupamientos que disputaron los principales sindicatos. Pero, a pesar de la aparente victoria de las tendencias que defendían una estrategia alternativa en las elecciones sindicales, esa perspectiva no consiguió hacerse hegemónica en la clase y fue finalmente derrotada hacia el año '89, como antesala de la derrota general.

No se logró consolidar una estrategia obrera distinta a la que representaba la dirección tradicional. Los nuevos dirigentes parecieron "acostumbrarse" a la administración de la compleja estructura sindical, perdiendo protagonismo su convicción de potenciar la confrontación callejera y la unidad de la clase. Además, la estructura centralizada dificultaba el manejo de fondos propios para las seccionales que se planteasen en "rebeldía" con respecto a la conducción nacional.

Estos factores fueron relevantes; pero entiendo que el límite clave de estos intentos de construir un sindicalismo alternativo fue que la perspectiva corporativa seguía siendo hegemónica entre los trabajadores. Ello no implicaba que la clase obrera, como sujeto, y el sindicato, como forma organizativa, no continuasen siendo la clave de la conflictividad y de los posibles cambios sociales. Lo que sí conllevaba era la dificultad para interpelar a otros colectivos y conformar una opción de transformación social: se hicieron visibles los límites de la forma sindical para que los trabajadores consoliden una verdadera ruptura con la situación de subalternización económica y política que sufren bajo el capitalismo.

Esa limitación a la defensa corporativa de sus intereses en tanto grupo profesional, que en este trabajo veo ratificada, no puede llevar a perder de vista su potencialidad: es ese 
movimiento obrero quien sigue siendo el único capaz de conmover y transformar la sociedad. Por ello es cada vez más necesario estudiarlo y comprenderlo.

\section{Referencias Bibliográficas}

\section{Impresas:}

Aiziczon Fernando, "Construyendo tradiciones. Activistas de izquierda en las luchas de los obreros de la construcción de Neuquén a fines de los años '80", Izquierdas, 5, Santiago, IDEA-USACH, julio 2009.

Aiziczon F., "Militantes chilenos en Neuquén. La experiencia de la Interbarrial durante los años '80", Izquierdas 21, Santiago, IDEA-USACH, Octubre 2014, 67-82.

Aiziczon F., "Trayectorias militantes, izquierda y política sindical: la intervención del MAS en Sierra Grande a través de las vivencias de un obrero minero, Patagonia argentina (1988-1991)", Izquierdas, 31, Santiago, IDEA-USACH, diciembre 2016, 46-70.

Altamirano Carlos, Peronismo y cultura de izquierda, Buenos Aires, Siglo XXI, 2011.

Araya Rodrigo, "Ha llegado la hora de decir basta. El movimiento sindical y la lucha por la democracia en Chile, 1973-1990", Izquierdas, 37, Santiago, IDEA-USACH, diciembre 2017, 191-211.

Araya R., Del combate a la dictadura a la preservación de la democracia. Movimiento sindical y políticas de concertación social. Los casos de Chile y España (1975-1994), Tesis Doctoral Univ. Autónoma de Barcelona, en http://www.tesisenred.net/bitstream/handle/10803/96357/rag1de1.pdf?sequence=1, 2012.

Aruguete Eugenia, "Lucha política y conflicto de clases en la posdictadura. Límites a la constitución de alianzas policlasistas durante la administración Alfonsín", Alfredo Pucciarelli (coord.), Los años de Alfonsín ¿El poder de la democracia o la democracia del poder?, Buenos Aires, Siglo XXI, 2006, 413 460.

Bartoletti Julieta, "Dilemas de la Izquierda Peronista", Actas III Jornadas de Sociología de la UNLP, La Plata, UNLP, 2003, http://www.memoria.fahce.unlp.edu.ar/trab_eventos/ev.6847/ev.6847.pdf.

Belardinelli Pablo, "El marco político de la conflictividad obrera", Ernesto Villanueva (coord.), Conflicto Obrero. Transición política, conflictividad obrera y comportamiento sindical en la Argentina 1984-1989, Buenos Aires, UNQ, 1994, 103-149.

Bonnet Alberto, La hegemonía menemista, Buenos Aires, Prometeo, 2008.

Calello Osvaldo y Daniel Parcero, De Vandor a Ubaldini. Tomo 1 y 2, Buenos Aires, CEAL, 1984.

Caprano Raquel y Dora Palacios, "Economías de enclave y estrategias empresariales. El Caso Aluar", Actas XII Jornadas Interescuelas Departamentos de Historia, Bariloche, UNCo, 2009.

Cimillo Elsa, Bloque textil: dinámica en la provincia del Chubut. 1973-1984, Buenos Aires, CFICEPAL, 1985, 12-13.

Correa Mauricio, "El fracaso de la concepción sindical vandorista de la UOM San Nicolás en el conflicto por la privatización de SOMISA", Historia Regional No24, Villa Constitución, ISP Nº3, 2006, 65-86.

Cotarelo María Celia, "Conflicto social en Argentina entre 2002 y 2008", Actas XII Jornadas Interescuelas de Historia, Bariloche. UNCo. 2009.

Cotarelo M. C., "El motín de Santiago del Estero. Argentina, diciembre de 1993", PIMSA DT No 19, Buenos Aires, PIMSA, 1999, 83-119.

Cotarelo M. C., Argentina (1993-2010). El proceso de formación de una fuerza social; Buenos Aires, PIMSA-Imago Mundi, 2016. 
Dawyd Darío, "El nuevo autoritarismo burocrático y el sindicalismo peronista. Análisis de la 'participación' junto al gobierno militar de Onganía en la Argentina de los años sesenta: del 'nuevo orden social' al 'Cordobazo', Confluenze. Rivista di Studi Iberoamericani, Italia, Università di Bologna, 2012.

Delgado Felipe y Miguel Maugard, "Movilización y organización popular en dictadura: las jornadas de protesta nacional en Arica (1980-1986)", Izquierdas, 39, Santiago, IDEA-USACH, abril 2018, 34-56.

Díaz César y Mario Giménez "La Nación y el sindicalismo en 1983: la crisis, las huelgas y la democratización, Revista internacional de Historia de la Comunicación, No99, 2017, 92-107).

Dossier sobre burocracia sindical, número 7 de la revista "Nuevo Topo" (Buenos Aires, Prometeo, 2010)

Dossier sobre burocracia sindical, número 8 de la revista "Archivos del Movimiento Obrero y la Izquierda" (Buenos Aires, Imago Mundi, 2016).

Eder Klaus, "La institucionalización de la acción colectiva. Hacia una nueva problemática teórica en el análisis de los movimientos sociales", Pedro Ibarra y Benjamín Tejerina (edit.) Los Movimientos Sociales. Transformaciones políticas y cambio cultural; Madrid, Trotta, 1998, 337-359.

Fernández Arturo, Las prácticas sociopolíticas del sindicalismo Tomo 1 y 2 (1955-1985), Buenos Aires, CEAL, 1988.

Fradkin Raúl y Jorge Gelman, Juan Manuel de Rosas. La construcción de un liderazgo político, Buenos Aires, Edhasa, 2015.

Gatica Mónica, ¿Exilio, migración, destierro? Trabajadores chilenos en el noreste de Chubut (19732010), Buenos Aires, Prometeo, 2013.

Ghigliani Pablo, "La noción de derrota en la historia reciente del movimiento obrero argentino", Actas V Jornadas de Sociología de la UNLP, La Plata, UNLP, en https://www.aacademica.org/000096/570.pdf.

Giarracca Norma, "Argentina 1991-2001: Una década de protesta que finaliza en un comienzo. La mirada desde el país interior", Argumentos, 1 (1), diciembre 2002, http://www.revistaargumentos.com.ar/index.php/argumentos/article/viewFile/23/20

Godio Julio (comp.), El debate sindical nacional e internacional, Buenos Aires, CEAL, 1984.

Gordillo Mónica, "¿Cómo enfrentar a las burocracias sindicales? Algunas estrategias democratizadoras en los 80", Archivos de Historia del Movimiento Obrero y la Izquierda Nº , Buenos Aires, ProHMOI, 2016, 55-76

Gramsci Antonio, Notas sobre Maquiavelo, sobre la política y sobre el estado moderno, Buenos Aires, Nueva Visión, 1999, 99.

Grigera Juan, "El concepto de desindustrialización como peculiaridad argentina", Revista de Estudios Sociales y Marítimos N5, UNMdP, 2013, 187-195.

Guevara Sebastián, "Lucha de clases y acumulación de capital en Argentina 1973-1983: discusiones a partir de los estudios sobre la acción política obrera", Izquierdas, 33, Santiago, IDEA-USACH, mayo 2017, 66-89.

Harari Ianina, "¿Qué es la burocracia sindical?", Razón y Revolución 30, Buenos Aires, CEICS, 2017, 51-67.

Ibarra Horacio y Carlos Hernández, Estado, Economía y Sociedad. Trelew y su hinterland: 1989-1999, Trelew, INSHIS-UNP, 2017.

Ibarra H., Patagonia Sur. La construcción interrumpida de un proceso de desarrollo regional, Trelew, UNPSJB, mimeo, 1997.

Iñigo Carrera Nicolás y M. Cotarelo, "Algunos rasgos de la rebelión en Argentina 1993-2001", PIMSA 2004, Buenos Aires, PIMSA, 2004, 125-138.

Iñigo Carrera N. y otros, "La revuelta. Argentina 1989/90"; en PIMSA DT No 4, Buenos Aires, PIMSA, 1995. 
Iñigo Carrera N., "La huelga general como indicador de momentos de ascenso y descenso en la lucha de la clase obrera. Argentina 1984-2002", Actas XII Jornadas Interesc. de Hist., Bariloche, UNCo, en CD, 2009.

Iñigo Carrera N., La otra estrategia. La voluntad revolucionaria (1930-1935), Buenos Aires, Imago Mundi, 2016.

Jelin Elizabeth (comp.), Los nuevos movimientos sociales, Tomo 1 (Mujeres. Rock Nacional) y Tomo 2 (Derechos Humanos. Obreros. Barrios), Buenos Aires, CEAL, 1985.

Jelin E. (comp.) Movimientos sociales y democracia emergente, Tomo 1 y 2, Buenos Aires, CEAL, 1987

Massano Juan Pedro, Reorganización del Movimiento Obrero Sindicalizado en la posdictadura argentina: El caso de la "Ley Mucci", FHACE-UNLP, 2012, http://www.memoria.fahce.unlp.edu.ar/tesis/te.707/te.707.pdf.

Matamoros Christian, "Profesores comunistas y sindicalismo docente en la lucha antidictatorial, Chile 1981-1987", Izquierdas, 32, Santiago, IDEA-USACH, marzo 2017, 203-234.

Matsushita Hiroshi, Movimiento obrero argentino 1930-1945, Buenos Aires, Hyspamérica, 1986.

Melucci Alberto, Acción colectiva, vida cotidiana y democracia, México D.F.; Colegio de México, 1999. Molinaro Leandro, "El reposicionamiento de la burocracia sindical en el ocaso del 'Proceso'(julio de 1982-diciembre de 1983", Archivos de Historia del Movimiento Obrero y la Izquierda Nº, Buenos Aires, ProHMOI, 2016, 33-54

Molinaro L., "La democracia del Nunca más y el movimiento obrero. La ocupación obrera de la planta Ford de General Pacheco en 1985", Archivos de Historia del Movimiento Obrero y la Izquierda N², Buenos Aires, ProHMOI, 2013, 55-76.

Molinaro L., Demonización y Reconciliación nacional, Buenos Aires, Colisión, 2013.

Morales Virginia, "Reconfiguraciones identitarias en la Asociación Madres de Plaza de Mayo: lucha contra la impunidad, radicalización y "giro a la izquierda" (1983-2003)", Izquierdas, 34, Santiago, IDEA-USACH, julio 2017, 125-149.

Nieto Agustín, "Notas críticas en torno al sentido común historiográfico sobre 'el anarquismo argentino", A Contracorriente Vol.7, No.3, North Carolina State University, Spring 2010, 219-248.

Offe Claus, Partidos políticos y nuevos movimientos sociales, Madrid. Edit. Sistema, 1992.

Olson Mancur, La lógica de la acción colectiva, México, Limusa, 1992.

Oyarzo Vidal Gemita, "Voces de los 80. De los Actores colectivos a los sentidos históricos de las luchas antidictatoriales en Chile (1973-1989)", Izquierdas, 8, Santiago, IDEA-USACH, 2010, 1-14.

Paniquelli María y Bruno Sancci, El Chubutazo: octubre de 1990, Buenos Aires, De los cuatro vientos, 2006.

Pérez Álvarez Gonzalo, Patagonia, conflictividad social y neoliberalismo 1990-2005, Buenos Aires, Imago Mundi, 2013.

Pérez Álvarez G., "'Con hilos rotos vamos tejiendo otra historia' Lucha y experiencia obrera en el parque textil de Trelew", Sociohistórica No 27, La Plata, FAHCE-UNLP, 2011, 13-39.

Pérez Álvarez G., "Conflictos sociales en el nordeste de Chubut: cambios y permanencias a través de veinte años de registro (1986-2005)", Estudios del Trabajo N52, Buenos Aires, ASET, 2016, http://www.scielo.org.ar/scielo.php?script=sci_arttext\&pid=S2545-77562016000200003.

Pérez Álvarez G., "Dictadura, democracia y clase obrera: los trabajadores ante el retorno al régimen constitucional en el noreste de Chubut", Avances del CESOR, No 12, Rosario, UNR, Primer semestre 2015, 71-88.

Pérez Álvarez G., "El aporte de la migración chilena a la formación de una nueva clase obrera en el noreste de Chubut: 1956-1989", Cuadernos de Historia, N 43, Santiago, Universidad de Chile, 2015, 59-81. 
Pérez Álvarez G., "Experiencia obrera, construcciones sindicales y organizaciones políticas de la clase obrera. Los trabajadores de la Patagonia argentina durante la década del '80", Historia Actual Online ${ }^{\circ}$ 37, Cádiz, Universidad de Cádiz, 2015, 53-68.

Pérez Álvarez G., "Organizaciones y propuestas políticas en el conflicto social del noreste de Chubut 1990-1991", Actas IV Jornadas Latinoamericanas Hacer La Historia, La Pampa, UNLPampa, 2006, en CD.

Pérez Álvarez G., "Paternalismo, experiencia obrera y desarrollo del régimen de gran industria: la historia de ALUAR", Mundos do Trabalho vol. 3 n $^{\circ}$, julho-dezembro 2011, Universidade Federal de Santa Catarina, 130-150.

Pérez Álvarez G., "Trabajadores y trabajadoras en tres procesos de industrialización acelerada: Manaus (Amazonia-Brasil), Trelew (Patagonia-Argentina) y Vitoria-Gasteiz (País Vasco-España)", en Ayer, Madrid, Marcial Pons, en prensa.

Pérez Álvarez G., "Una discusión con el concepto de 'des industrialización' desde el caso del noreste de Chubut", Revista de Estudios Sociales y Marítimos N5, UNMdP, 2013 Revista de Estudios Sociales y Marítimos N5, UNMdP, 2013, 175-185.

Pérez Álvarez G., "Amazônia Brasileira e Patagônia Argentina: planos de desenvolvimento e soberania nacional", Estudos Avançados Vol.30 No 88, San Pablo, USP, Setembro-Dezembro 2016, 117-138.

Pérez Álvarez G., "Lucha y memoria obrera en el noreste del Chubut. Una aproximación desde la fábrica Modecraft 1990-1991" en Historia Antropología y Fuentes Orales, No 41, Barcelona, 2009, 25 48.

Piva Adrián, "El desacople entre los ciclos del conflicto obrero y la acción de las cúpulas sindicales en Argentina (1989-2001)", Actas XII Jornadas Interesc. de Hist., Bariloche, UNCo, en CD, 2009.

Pozzi Pablo y Alejandro Schneider, Combatiendo el capital: Crisis y Recomposición de la clase obrera argentina (1985-1993), Buenos Aires, El Bloque Edit., 1994.

Prospitti Agustín, "El sindicalismo combativo en la Unión Obrera Metalúrgica Villa Constitución y el desafío de su reorganización en el retorno de la democracia", Izquierdas, 24, Santiago, IDEA-USACH, julio 2015, 82-107.

Pucciarelli Alfredo (coord.), Los años de Alfonsín ¿El poder de la democracia o la democracia del poder?, Buenos Aires, Siglo XXI, 2006.

Rougier Marcelo, Estado y empresarios de la industria del aluminio en la Argentina. El caso Aluar, Buenos Aires, UNQ, 2011.

Ruiz Patricio, "Hacia una 'transición modelo': influencia y significación de la transición española en la oposición chilena a la dictadura (1980-1987)", Izquierdas, 24, Santiago, IDEA-USACH, julio 2015, 127 149.

Santella Agustín, "El debate sobre bases contra direcciones sindicales revitalizado", Estudios del Trabajo, Buenos Aires, ASET, 2017, http://www.scielo.org.ar/pdf/et/n53/n53a04.pdf.

Schiavi Marcos, "La Asociación Obrera Textil (1945-1955): La dinámica sindical en los sindicatos peronistas", Anuario IEHS 28, Tandil, UNCPBA, 2013, 313-327.

Schiavi M., "Conflicto y organización sindical en los orígenes del peronismo: la conformación de la Asociación Obrera Textil", Archivos de historia del movimiento obrero y la izquierda $n^{\circ} 2$, Buenos Aires, ProHMOI, 2013, 9-32.

Senén González Santiago y Fabián Bosoer, El hombre de hierro. Vandor, Rucci, Miguel, Brunelli, Buenos Aires, Corregidor, 1993.

Stortini Julio, "Rosas a consideración. Historia y memoria durante el menemismo", Actas XI Jornadas Interescuelas/Departamentos de Historia, San Miguel, Universidad de Tucumán, 2007.

Touraine Alain, Los movimientos sociales, Buenos Aires, Almagesto, 1991.

Villanueva Ernesto (coord.) Conflicto obrero. Transición política, conflictividad obrera y comportamiento sindical en la Argentina 1984-1989, Buenos Aires, UNQ, 1994. 
Vommaro Gabriel, "Cuando el pasado es superado por el presente: las elecciones presidenciales de 1983 y la construcción de un nuevo tiempo político en Argentina", Alfredo Pucciarelli (coord.), Los años de Alfonsín ¿El poder de la democracia o la democracia del poder?, Buenos Aires, Siglo XXI, 2006, 245-288.

\section{Publicaciones periodísticas:}

Diario El Chubut, ediciones varias.

Diario Jornada, diversas ediciones: edición del 10/1/1984; p. 6; edición del 18/10/1984; p.8; edición del 22/1/1984; p. 8; edición del 27/3/1984; p. 2; edición del 27/4/1984; p. 2; edición del 29/4/1987, p. 8; edición del 3/1/1984; p. 6; edición del 3/12/1985; p. 2; edición del 3/12/1985; p. 2; edición del 30/3/1984; p. 7; edición del 9/1/1984; p. 20, y otras.

Portales de Internet: http://www.diarioinedito.com/Nota/14886.

\section{Entrevistas:}

Entrevistas a militantes obreros de diversas fracciones de la clase. Especialmente aportaron para este trabajo los siguientes entrevistados:

Fernando Rodríguez, entrevista realizada el 2 de Mayo de 2008. Obrero de Aluar.

Héctor Rolón, entrevista realizada el 9 de Mayo de 2008. Obrero de Aluar, integró la "Rafael Uribe".

Daniel Roterio, entrevista realizada el 4 de abril de 2012. Militante del MAS (Movimiento Al Socialismo) y de la agrupación textil $1^{\circ}$ de Mayo.

Miguel Zalazar, entrevista realizada el 15 de junio de 2007. Militante del PI (Partido Intransigente, de izquierda moderada) y de la agrupación textil $1^{\circ}$ de Mayo.

Gerardo Capone, entrevista realizada el 2 de Mayo de 2008. Ligado al Partido Comunista, fue activo militante de la Rafael Uribe.

José Luis Giussi, entrevista realizada el 6 de agosto de 2016. Fue obrero de Aluar y activo dirigente de la Rafael Uribe.

René Pérez, entrevista realizada el 4 de julio de 2009 y el 23 de septiembre de 2016. René es chileno, militante textil ligado al Partido Comunista y uno de los dirigentes de la agrupación $1^{\circ}$ de Mayo.

Juan Alff, entrevista realizada el 9 de junio de 2007 y el 21 de septiembre de 2016. Era militante del PJ y trabajador textil. Actualmente es dirigente de la Coordinadora de Trabajadores Desocupados "Aníbal Verón".

Alfonso Islas, entrevista realizada el 7 de agosto de 2015. Ex obrero de la pesca de origen chileno, que luego fue dirigente de la Agrupación Evita de Desocupados. 